\section{International Scientific Journal Theoretical \& Applied Science}

\author{
p-ISSN: 2308-4944 (print) e-ISSN: 2409-0085 (online) \\ Year: $2016 \quad$ Issue: $11 \quad$ Volume: 43 \\ Published: 26.11.2016 http://T-Science.org
}

SECTION 6. Metallurgy and energy.
E.S. Belyaev

Candidate of technical Sciences, associate professor of «Materials science, technology of materials and heat treatment of metals») Nizhny Novgorod State Technical University n.a. R.E. Alekseev yaneck@bk.ru

\section{E.V. Tumina}

Master student of the Department «Materials science, technology of materials and heat treatment of metals» Nizhny Novgorod State Technical University n.a. R.E. Alekseev

N. V. Makarov

Postgraduate student of the Department «Materials science, technology of materials and heat treatment of metals»

Nizhny Novgorod State Technical University n.a. R.E. Alekseev

\title{
APPLICATION OF THE METHOD OF MATHEMATICAL PLANNING OF EXPERIMENT IN THE STUDY OF COMPLEX HEAT TREATMENT PROCESS OF STEEL 38XH3MФA
}

\footnotetext{
Abstract: We consider the technology is complex, the volume and surface hardening steel 38XH3MФA. The effect of laser radiation on a steel $38 X H 3 М \Phi A$ with different initial bulk thermal treatment using the method of mathematical planning of experiments. Drive technology volumetric heat treatment and laser hardening steel $38 X Н 3 М Ф A$ in various modes. The influence factors and the mechanism of hardness modification. When analyzing the results compared to micro-hardness hardened zone after complex processing.

Selects the optimum mode to achieve the desired values of physical and mechanical characteristics of the surface.

Key words: mathematical planning of experiment, laser processing, the processing mode, the power density, beam speed, microhardness.

Language: Russian

Citation: Belyaev ES, Tumina EV, Makarov NV (2016) APPLICATION OF THE METHOD OF MATHEMATICAL PLANNING OF EXPERIMENT IN THE STUDY OF COMPLEX HEAT TREATMENT PROCESS OF STEEL 38XH3MФA. ISJ Theoretical \& Applied Science, 11 (43): 118-126.

Soi: http://s-o-i.org/1.1/TAS-11-43-21 Doi: crossef http://dx.doi.org/10.15863/TAS.2016.11.43.21

\section{ПРИМЕНЕНИЕ МЕТОДА МАТЕМАТИЧЕСКОГО ПЛАНИРОВАНИЯ ЭКСПЕРИМЕНТА ПРИ} ИЗУЧЕНИИ ПРОЦЕССА КОМПЛЕКСНОЙ ТЕРМИЧЕСКОЙ ОБРАБОТКИ СТАЛИ З8ХНЗМФА

Аннотация: Рассматриваются технология комплексного, объемного и поверхностного упрочнения

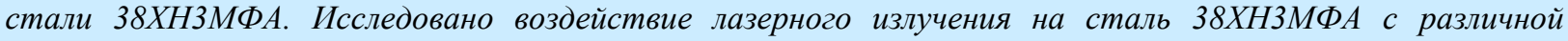
исходной объемной термической обработкой с применением метода математического планирования экспериментов. Приводятся технологии объемной термообработки и лазерного упрочнения стали З8ХНЗМФА по различным режимам. Проведен анализ влияния факторов и рассмотрен механизм изменения микротвердости. При анализе результатов сравнивается микротвердость упрочненной зоны после комплексной обработки.

Производится выбор оптимального режима для достижения требуемых значений физикомеханических характеристик поверхности.

Ключевые слова: математическое планирование эксперимента, лазерная обработка, режим обработки, плотность мощчности, скорость луча, микротвердость.
} 


\section{Введение}

Лазерная поверхностная обработка позволяет упрочнять поверхность различных изделий из стали. В результате комплексной термической обработки (объемная и последующая лазерная термическая обработка) достигается твердость выше, чем только после объемной термической обработке, что обеспечивает большую износостойкость поверхности. [1-5]

Применение методов математического планирования $[4,5]$ сокращает количество экспериментальной работы и позволяет получить наиболее полное представление об исследуемой системе и легко оптимизировать процесс по параметру отклика.

\section{Объект исследования}

В настоящем исследовании используется сталь 38ХНЗМФА ГОСТ 4543 - 71. Рассматриваемая сталь является улучшаемой и относится к перлитному классу. Химический состав стали приводится в таблице 1 [6,7].

Химический состав стали 38ХНЗМФА

Таблица 1

\begin{tabular}{|c|c|c|c|c|}
\hline \multicolumn{5}{|c|}{ Химический состав, масс.\% } \\
\hline $\boldsymbol{C}$ & $\boldsymbol{S i}$ & $\boldsymbol{M n}$ & $\boldsymbol{C r}$ & $\boldsymbol{N i}$ \\
\hline $0,33-0,4$ & $0,17-0,37$ & $0,25-0,5$ & $1,2-1,5$ & $3,0-3,5$ \\
\hline \multicolumn{5}{|c|}{ Химический состав, масс.\% } \\
\hline $\boldsymbol{M o}$ & $\boldsymbol{V}$ & $\boldsymbol{C u}$ & $\boldsymbol{S}$ & $\boldsymbol{P}$ \\
\hline $0,35-0,45$ & $0,1-0,18$ & до 0,3 & до 0,025 & до 0,025 \\
\hline
\end{tabular}

Для лазерной обработки использовались образцы призматической формы с размерами 10x10x30 мм. На образцах получали четыре «лазерные дорожки» по различным режимам (рисунок 1). Лазерная обработка проводилась на лазерной технологической установке «Латус-31», длина волны лазерного излучения $\_10,6$ мкм.

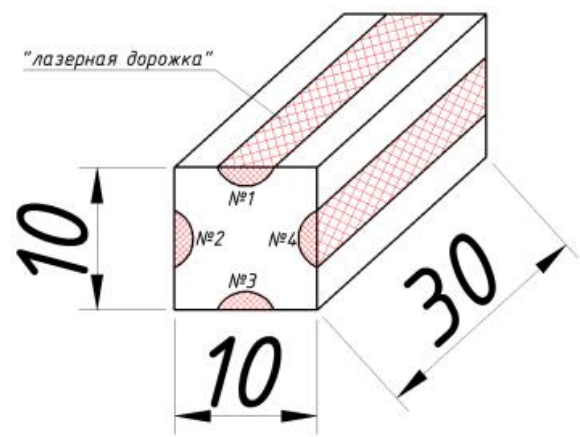

Рисунок 1 - Схема лазерной обработки образцов

\section{Планирование эксперимента}

Лазерная закалка поверхности зависит как минимум от двух факторов: от плотности мощности лазерного излучения и времени воздействия излучения $\mathrm{c}$ данной плотностью мощности. При лазерной обработке большое значение имеет исходное состояние структуры стали.

Для учета нескольких факторов при проведении эксперимента необходимо использовать методы математического планирования. Это дает следующие преимущества:

уменьшение

количества экспериментальной работы;

- возможность количественного описания полученных результатов в одном уравнении.

При выполнении настоящей работы исследовалось влияние плотности мощности лазерного излучения, скорости обработки и структурного состояния материала (температуры отпуска). Реализован полный факторный эксперимент по плану $\mathrm{N}=2^{\mathrm{K}}$.

План $\mathrm{N}=2^{\mathrm{K}}$, где $\mathrm{K}=3$ (число факторов), 2 число уровней (верхний +1 и нижний -1$), \mathrm{N}=2^{3}=8$ - число опытов.

\section{Составление матрицы планирования эксперимента и выбор параметров оптимизации}

Варьируемыми факторами в настоящем исследовании, как указано выше, являются плотность мощности $W$, скорость обработки $v$ и структурное состояние стали 38ХНЗМФА, в данном случае различная температура отпуска после закалки.

Введем обозначение указанных факторов:

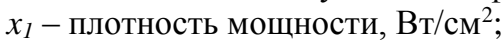

ISPC Education and Innovation, 


\begin{tabular}{|c|c|c|c|c|c|c|}
\hline Impact Factor: & $\begin{array}{l}\text { ISRA (India) } \\
\text { ISI (Dubai, UAB } \\
\text { GIF (Australia) } \\
\text { JIF }\end{array}$ & $\begin{array}{r}=1.344 \\
=0.829 \\
=0.564 \\
=1.500\end{array}$ & $\begin{array}{l}\text { SIS (USA) } \\
\text { PИHЦ (Russia) } \\
\text { ESJI (KZ) } \\
\text { SJIF (Morocco) }\end{array}$ & $\begin{array}{l}=0.912 \\
=0.234 \\
=1.042 \\
=2.031\end{array}$ & $\begin{array}{l}\text { ICV (Poland) } \\
\text { PIF (India) } \\
\text { IBI (India) }\end{array}$ & $\begin{array}{l}=6.630 \\
=1.940 \\
=4.260\end{array}$ \\
\hline
\end{tabular}
$\mathrm{MM} / \mathrm{c}$;

$x_{2}$ - скорость перемещения лазерного луча,

$x_{3}$ - температура отпуска, ${ }^{\circ} \mathrm{C}$.
Исходные значения факторов $x_{1}, x_{2}$ и $x_{3}$ основной уровень, интервалы варьирования, подсчитанные значения верхнего и нижнего значений факторов приведены в таблице 2.

Таблица 2

Уровни факторов

\begin{tabular}{|l|c|c|c|c|}
\hline \multirow{2}{*}{ Исходные данные } & \multirow{2}{*}{$\begin{array}{c}\text { Кодированное } \\
\text { значение } \\
\text { факторов } x_{i}\end{array}$} & $\begin{array}{c}\text { Нлотность } \\
\text { мощности, Вт/см }{ }^{2}\end{array}$ & $\begin{array}{c}\text { Скорость } \\
\text { обработки, мм/сек }\end{array}$ & $\begin{array}{c}\text { Температура } \\
\text { отпуска, }{ }^{\circ} \mathrm{C}\end{array}$ \\
\cline { 3 - 5 } & 0 & $x_{1 \text { нат. }}$ & $x_{2 \text { Нат. }}$ & $x_{3 \text { нат. }}$ \\
\hline $\begin{array}{l}\text { Основной уровень } \\
x_{i} 0\end{array}$ & - & $1,0 \cdot 10^{4}$ & 15 & 400 \\
\hline $\begin{array}{l}\text { Интервал } \\
\text { изменения } \Delta x_{i}\end{array}$ & -1 & $0,2 \cdot 10^{4}$ & 5 & 200 \\
\hline $\begin{array}{l}\text { Верхний уровень } \\
x_{i} 0^{+} \Delta x_{i}\end{array}$ & -1 & $1,2 \cdot 10^{4}$ & 20 & 600 \\
\hline $\begin{array}{l}\text { Нижний уровень } \\
x_{i} 0_{-} \Delta x_{i}\end{array}$ & $0,8 \cdot 10^{4}$ & 10 & 200 \\
\hline
\end{tabular}

Составляем матрицу планирования экспериментов в кодированном и натуральном масштабах, изменяя факторы на двух уровнях: верхнем и нижнем. Дополнительно запланируем четыре параллельных опыта на основном уровне для определения ошибки опыта. Внесем в матрицу планирования фиктивный фактор «Центр» для оценки кривизны поверхности отклика. Составленная матрица планирования эксперимента представлена в таблице 3.

Таблица 3

Матрица планирования эксперимента

\begin{tabular}{|c|c|c|c|c|c|c|c|c|}
\hline \multirow{3}{*}{$\begin{array}{c}\text { № } \\
\text { опыта } \\
i\end{array}$} & \multicolumn{7}{|c|}{ Значения факторов } & \multirow{3}{*}{$\mathrm{HV}_{\text {max }}$} \\
\hline & \multirow{2}{*}{$\frac{x_{ц}}{\text { код. }}$} & \multicolumn{2}{|c|}{$x_{1}$} & \multicolumn{2}{|c|}{$x_{2}$} & \multicolumn{2}{|c|}{$x_{3}$} & \\
\hline & & код. & нат., $\%$ & код. & нат., \% & код. & нат., $\%$ & \\
\hline \multicolumn{9}{|c|}{ Опыты на верхнем и нижнем уровне } \\
\hline 1 & 0 & +1 & 1,2 & +1 & 20 & +1 & 600 & 5781 \\
\hline 2 & 0 & -1 & 0,8 & +1 & 20 & +1 & 600 & 5507 \\
\hline 3 & 0 & +1 & 1,2 & -1 & 10 & +1 & 600 & 7543 \\
\hline 4 & 0 & -1 & 0,8 & -1 & 10 & +1 & 600 & 6453 \\
\hline 5 & 0 & +1 & 1,2 & +1 & 20 & -1 & 200 & 6350 \\
\hline 6 & 0 & -1 & 0,8 & +1 & 20 & -1 & 200 & 6041 \\
\hline 7 & 0 & +1 & 1,2 & -1 & 10 & -1 & 200 & 5745 \\
\hline 8 & 0 & -1 & 0,8 & -1 & 10 & -1 & 200 & 4700 \\
\hline \multicolumn{9}{|c|}{ Параллельные опыты на основном уровне } \\
\hline $9-1$ & 1 & 0 & 1,0 & 0 & 15 & 0 & 400 & 4820 \\
\hline $10-2$ & 1 & 0 & 1,0 & 0 & 15 & 0 & 400 & 4855 \\
\hline $11-3$ & 1 & 0 & 1,0 & 0 & 15 & 0 & 400 & 4800 \\
\hline $12-4$ & 1 & 0 & 1,0 & 0 & 15 & 0 & 400 & 4834 \\
\hline
\end{tabular}

В качестве параметра оптимизации $y$ принимаем микротвердость по глубине ванны $H V_{50}$, МПа.

\section{Полученные результаты и их} статистическая обработка

Были получены результаты изменений микротвердости в зависимости от глубины 3ТВ. По значениям микротвердости построены графики еe распределения. Типичный график представлен на рис.2
Очевидно, что величина микротвердости $H V$ не является постоянной по глубине ванны. Условно график можно разделить на три области.

В первой области, которая начинается от поверхности образца, наблюдается линейный рост микротвердости. На поверхности образуется большое количество остаточного аустенита, который уменьшает микротвердость на этом участке. Вторая область - это область максимальной микротвердости $\left(H V_{\max }\right)$, которая

ISPC Education and Innovation, 
остается постоянной до определенной глубины, за счет мартенситного превращения из твердой фазы.

В третьей области происходит крутой спад микротвердости до минимального значения, т.к. этот слой металла нагревается ниже точки $A_{c l}$ и здесь образуются структуры отпуска. После чего значение $H V$ незначительно возрастает и остается постоянным вне 3ТВ [3].
В настоящем исследовании рассматривается изменение микротвердости при ее максимальных значениях - во второй области (рис. 2).

По данным (табл. 3) была разработана регрессионная математическая модель изменения максимальной микротвердости в зависимости от факторов. Уравнение регрессии в кодовом масштабе имеет вид:

$$
y=6015-1187,75 x_{L}+339,75 x_{1}-95,25 x_{2}+306 x_{3}-194 x_{1} x_{2}-581,75 x_{2} x_{3}
$$

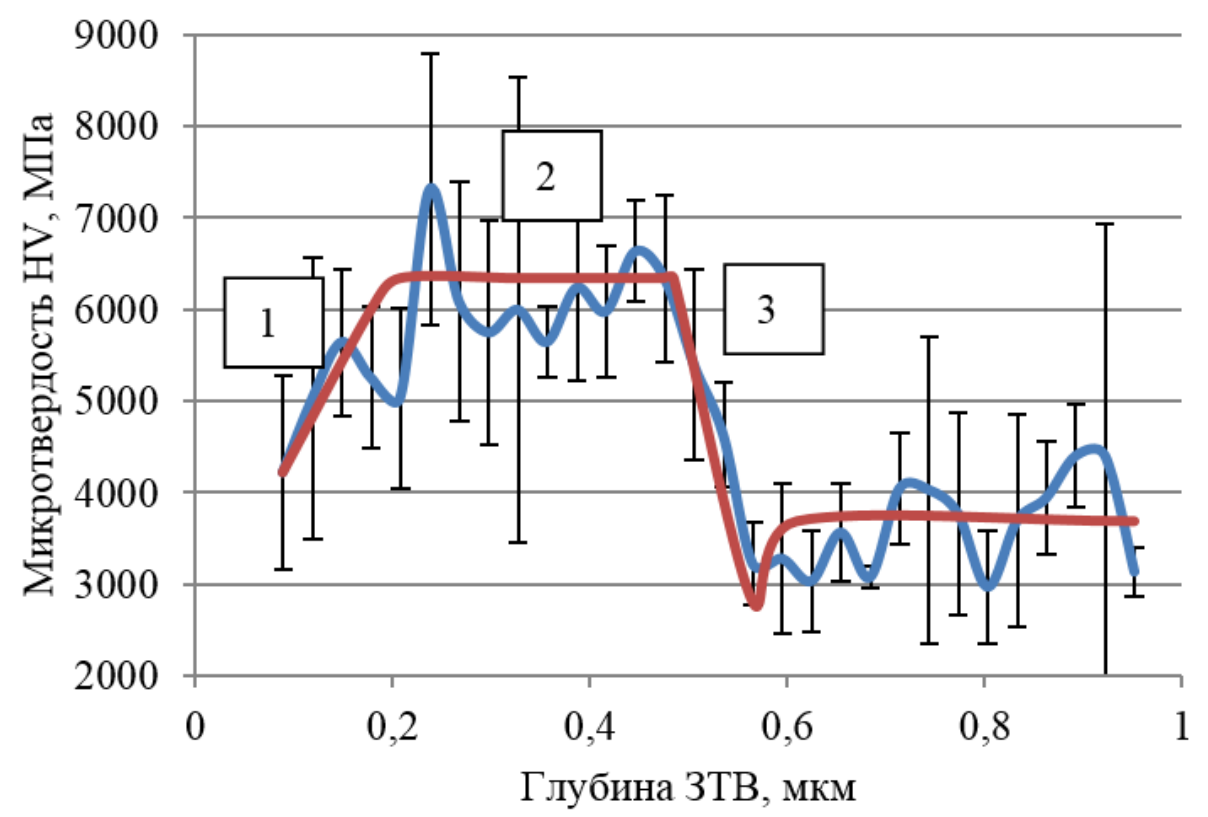
Рисунок 2- Типичный график зависимости микротвердости НV от глубины 3 ТВ (1 - область роста
микротвердости; 2 - область максимальных значений микротвердости; 3 - переходная зона)

В уравнение регрессии (1) вошли коэффициенты регрессии, уровень значимости которых менее 0,05 . Уровень значимости коэффициентов вычислялся на основании критерия Фишера. Фиктивный фактор «Центр» оказался статистически значимым. Численно регрессионный коэффициент фактора «Центр» изменяется от ноля до плюс единицы. В опытах на верхнем и нижнем уровнях принимается значение ноль, а на параллельном уровне значение плюс единица.

На рисунке 3 показана карта Парето стандартизированных эффектов, отражающая влияние каждого главного фактора и их взаимодействий на микротвердость $H V_{\text {max }}$.

Рассмотрим влияние каждого фактора на микротвердость в порядке уменьшения его влияния. Регрессионный коэффициент фактора «Центр» характеризует нелинейность, вогнутость поверхности отклика при движении от края плана к его центру, о чем свидетельствует отрицательный знак коэффициента.
Коэффициент парного взаимодействия скорости обработки и температуры отпуска характеризует структурно-энергетический фактор, связывающий исходное состояние микроструктуры и время воздействия лазерного излучения на поверхность рассматриваемой системы и значительно снижает микротвердость.

Регрессионный коэффициент плотности мощности повышает микротвердость.

Повышение температуры отпуска перед лазерной обработкой будет увеличивать максимальную микротвердость на поверхности рассматриваемой стали.

Парное взаимодействие плотности мощности и скорости обработки характеризует энергетические параметры лазерной обработки и снижает микротвердость в области режимов с большим энергетическим вкладом.

Регрессионный коэффициент скорости обработки показывает обратную зависимость, с ростом скорости обработки микротвердость снижается. 


\begin{tabular}{l|lrl|l|ll} 
& ISRA (India) & $=\mathbf{1 . 3 4 4}$ & SIS (USA) & $=\mathbf{0 . 9 1 2}$ & ICV (Poland) & $=\mathbf{6 . 6 3 0}$ \\
Impact Factor: & ISI (Dubai, UAE) $=\mathbf{0 . 8 2 9}$ & PUHU (Russia) $=\mathbf{0 . 2 3 4}$ & PIF (India) & $=\mathbf{1 . 9 4 0}$ \\
& GIF (Australia) & $\mathbf{0 . 5 6 4}$ & ESJI (KZ) & $=\mathbf{1 . 0 4 2}$ & IBI (India) & $\mathbf{4 . 2 6 0}$
\end{tabular}

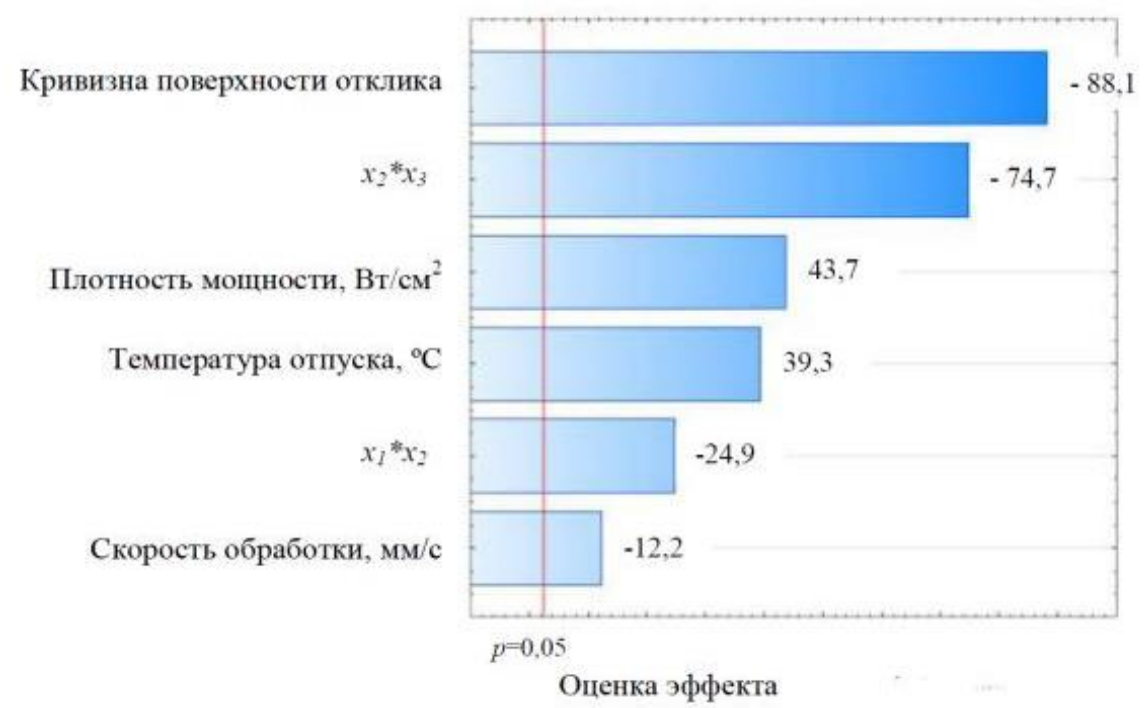

Рисунок 3 - Карта Парето стандартизированных эффектов

Обсуждение полученных результатов

В результате объемной закалки в масло стали 38ХНЗМФА и низкого отпуска - $200^{\circ} \mathrm{C}$, формируется структура бейнита, такая структуру имеет твердость по Роквеллу 52 HRC. Увеличение температуры отпуска приводит к распаду бейнита при температуре $t_{\text {omn }}=400^{\circ} \mathrm{C}$ в части объема, а при $t_{\text {отn }}=600^{\circ} \mathrm{C}$ во всем объеме образца на ферито-карбидную смесь различной дисперсности и получению бейнито-трооститной смеси $\left(t_{\text {omn }}=400^{\circ} \mathrm{C} ; 47 \mathrm{HRC}\right)$ и сорбита отпуска $\left(t_{\text {omn }}=600^{\circ} \mathrm{C} ; 42 \mathrm{HRC}\right)$. Содержание в данной стали сильных карбидообразователей существенно повышает ее отпускоустойчивость в интервале температур $400-600^{\circ} \mathrm{C}$ [8 - 10].

Воздействие лазерного излучения на полученные объемной термообработкой структуры имеет существенные различия. Рассмотрим изолинии микротвердости рассчитанные по уравнению 1 в координатах температура отпуска - плотность мощности (рис. 4).

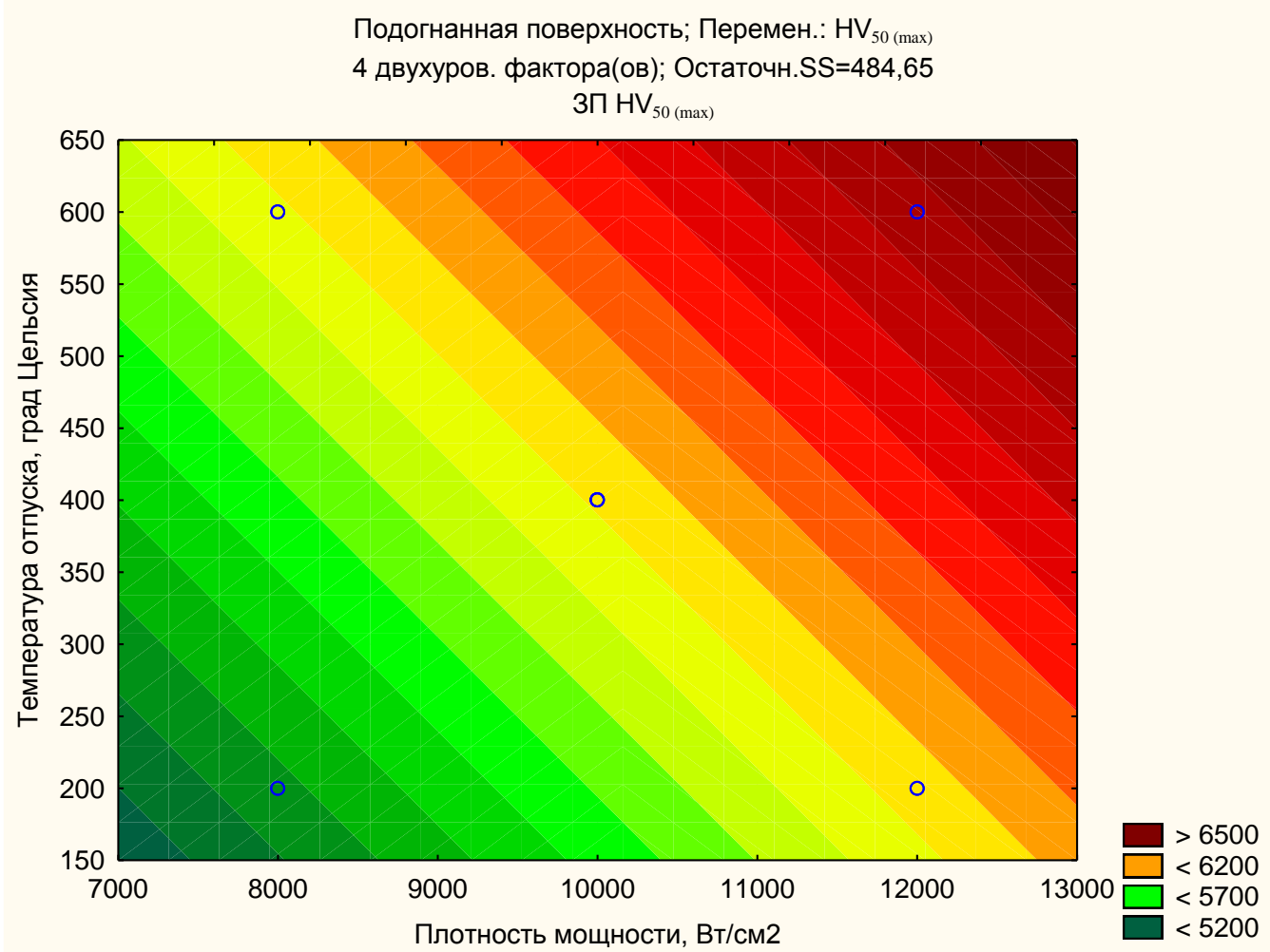

Рисунок 4 - Изменение микротвердости в зависимости от плотности мощности и температуры отпуска («Центр» - 0; скорость обработки - 15 мм/с)

ISPC Education and Innovation, 
В результате воздействия на бейнит отпуска лазерного излучения, микротвердость имеет наиболее низкие значения в рассматриваемом плане. При разогреве лазерным излучением поверхностные слои подвергаются вторичной закалке. При высоких скоростях нагрева и охлаждения образуется мартенсит закалки. Упрочнение области 2 (рис. 2) происходит за счет получения высокодисперсного мартенсита.

Исходная структура, содержащая карбиды, откликается на лазерную обработку лучше. Высокие скорости нагрева и охлаждения обеспечивают сохранение части дисперсных карбидов, полученных при объемной термической обработке.

Способствует получению больших значений микротвердости, при исходной структуре бейнита отпуска, применение более жесткого режима лазерной обработки (рисунок 5). Жесткий цикл лазерной обработки способствует получению высокодисперсной структуры.
Для получения больших значений микротвердости в случае исходной структуры сорбита режим лазерной обработки должен быть менее жестким за счет повышения скорости обработки. В данном случае упрочнение происходит так же за счет получения высокодисперсного мартенсита, но в присутствии исходной карбидной фазы. Следует так же отметить, что в случае наличия в структуре исходной карбидной фазы, значения микротвердости достигают максимальных значений.

При определенных значениях температуры отпуска и плотности мощности в исследуемом диапазоне полученная модель предсказывает наличие областей, в которых скорость обработки мало влияет на микротвердость (рис. 6). С ростом плотности мощности от $0,8 \cdot 10^{4}$ до $1,2 \cdot 10^{4} \mathrm{BT} / \mathrm{cm}^{2}$ эта температура снижается с 475 до $300^{\circ} \mathrm{C}$ соответственно. Наличие таких областей очевидно так же связано с наличием и дисперсностью карбидов в стали после отпуска.

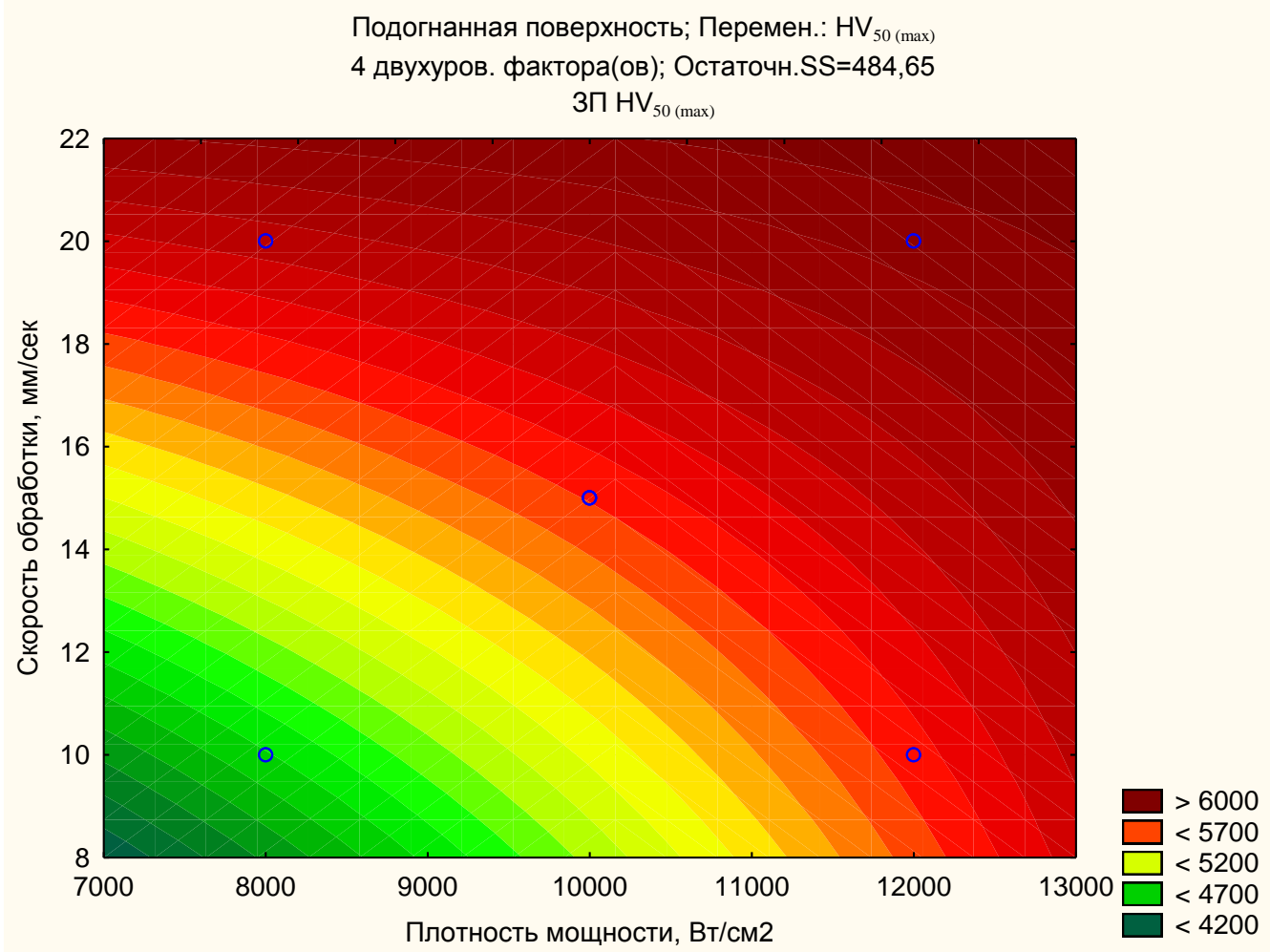

Рисунок 5 - Изменение микротвердости в зависимости от плотности мощности и скорости обработки («Центр» - 0; температура отпуска - $200{ }^{\circ} \mathrm{C}$ ) 


\begin{tabular}{l|lrl|l|ll} 
& ISRA (India) & $=\mathbf{1 . 3 4 4}$ & SIS (USA) & $=\mathbf{0 . 9 1 2}$ & ICV (Poland) & $=\mathbf{6 . 6 3 0}$ \\
Impact Factor: & ISI (Dubai, UAE) $=\mathbf{0 . 8 2 9}$ & PUHU (Russia) $=\mathbf{0 . 2 3 4}$ & PIF (India) & $=\mathbf{1 . 9 4 0}$ \\
& GIF (Australia) & $\mathbf{0 . 5 6 4}$ & ESJI (KZ) & $=\mathbf{1 . 0 4 2}$ & IBI (India) & $\mathbf{4 . 2 6 0}$
\end{tabular}

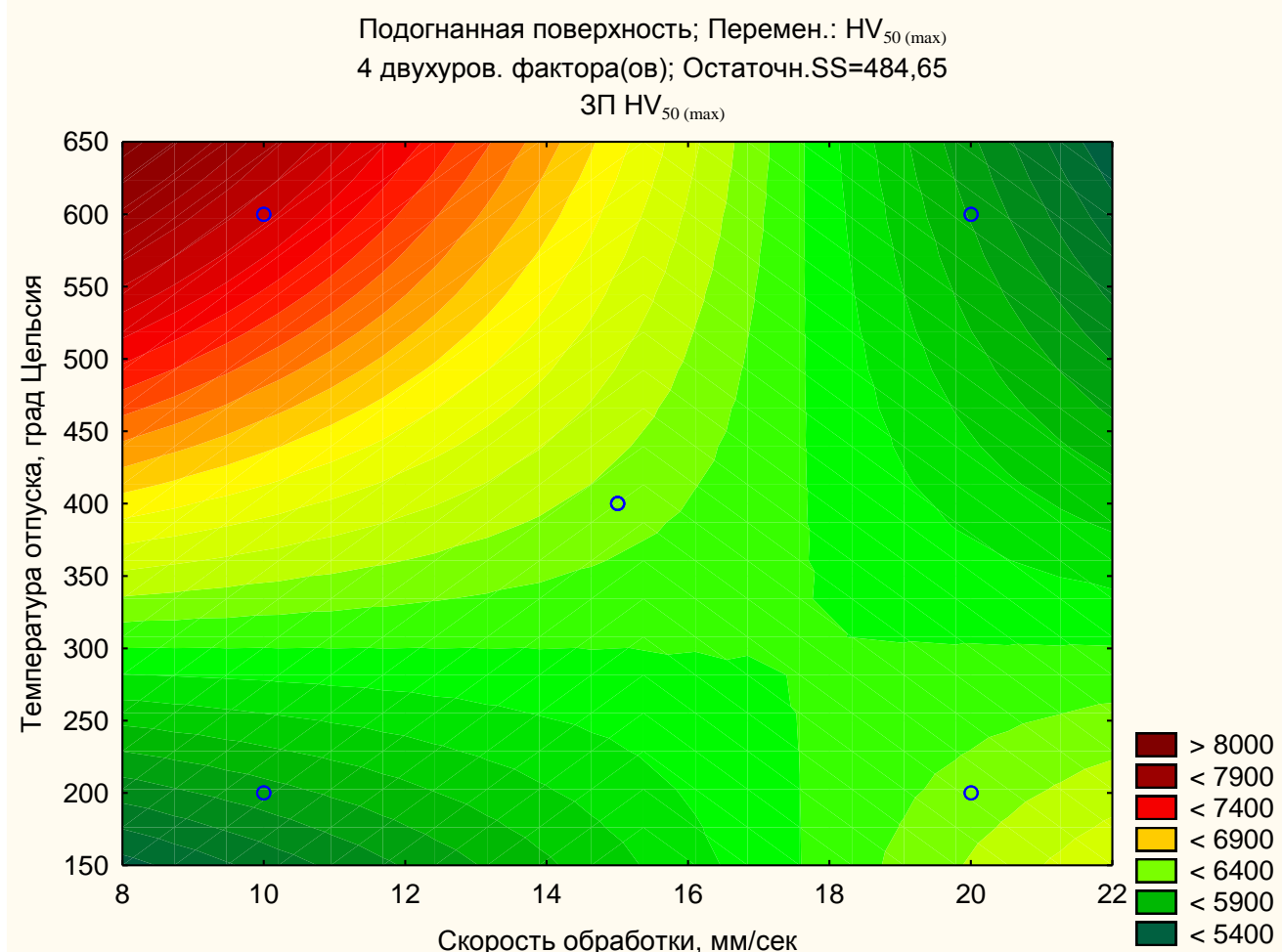

Рисунок 6 - Изменение микротвердости в зависимости от скорости обработки и температуры отпуска и («Центр» - 0; плотность мощности $\left.1,2 \cdot 10^{4} \mathrm{BT} / \mathrm{cm}^{2}\right)$

Значения микротвердости в таких областях изменяются нелинейно (рис. 4): $0,8 \cdot 10^{4} \mathrm{BT} / \mathrm{cm}^{2}$ 5700МПа; $1,0 \cdot 10^{4} \mathrm{BT} / \mathrm{cm}^{2}$ - 4700МПа; $1,2 \cdot 10^{4}$ Вт/см² - 6200МПа.

При исходной, преимущественно, бейнитной структуре и большой плотности мощности $\quad\left(t_{\text {omn }}=300^{\circ} \mathrm{C} ; \quad 1,2 \cdot 10^{4} \quad \mathrm{BT} / \mathrm{cm}^{2}\right)$ дисперсные карбиды в широком диапазоне энерговклада быстро растворяются в аустените и образуется сильнолегированный высокодисперсный мартенсит (6200 МПа).

При исходной структуре бейнита с продуктами его распада (троостит) и более низкой плотности мощности $\left(t_{\text {omn }}=375^{\circ} \mathrm{C} ; 1,0 \cdot 10^{4}\right.$ $\left.\mathrm{B} \mathrm{T} / \mathrm{cm}^{2}\right)$ в аустените растворяются меньшее количество дисперсных карбидов, содержащихся в исходном бейните. Карбидная фаза троостита за счет развивающихся диффузионных процессов укрупняется, что замедляет ее растворение в аустените. В результате образуется мартенсит менее легированный, чем в предыдущем случае, и микротвердость значительно снижается (4700 МПа).

При исходной троосто-сорбитной структуре и низкой плотности мощности $\left(t_{\text {omn }}=475^{\circ} \mathrm{C}\right.$; $\left.0,8 \cdot 10^{4} \mathrm{BT} / \mathrm{cm}^{2}\right)$ в аустените преимущественно растворяются наиболее дисперсные карбиды сорбита. В результате формируется достаточно легированный мартенсит и микротвердость в стационарной области становится выше (5700 МПа), чем с исходной структурой бейнита с продуктами его распада.

Таким образом, находится баланс между исходным содержанием карбидов после объемной термической обработки, их дисперсностью и энерговкладом от лазерной обработки, причем микротвердость будет выше в случае большего содержания карбидов, дисперсность которых позволяет быстро растворяться в аустените.

\section{Выбор оптимального режима лазерной обработки}

Применяя разработанную регрессионную модель для микротвердости, выбран оптимальный режим объемной и последующей лазерной обработки, при котором параметр оптимизации - микротвердость $H V_{\max }$ принимает наибольшие значения в рассмотренном диапазоне плотности мощности и скорости обработки.

Как отмечалось выше, максимальные значения микротвердости получены при $t_{\text {omn }}=$ $600^{\circ} \mathrm{C}$. Изолинии значений микротвердости при данной температуре отпуска показана на рисунке 7. 


\begin{tabular}{l|lrl|l|ll} 
& ISRA (India) & $=\mathbf{1 . 3 4 4}$ & SIS (USA) & $=\mathbf{0 . 9 1 2}$ & ICV (Poland) & $=\mathbf{6 . 6 3 0}$ \\
Impact Factor: & ISI (Dubai, UAE) $=\mathbf{0 . 8 2 9}$ & PUHU (Russia) $=\mathbf{0 . 2 3 4}$ & PIF (India) & $=\mathbf{1 . 9 4 0}$ \\
& GIF (Australia) & $\mathbf{0 . 5 6 4}$ & ESJI (KZ) & $=\mathbf{1 . 0 4 2}$ & IBI (India) & $\mathbf{4 . 2 6 0}$
\end{tabular}

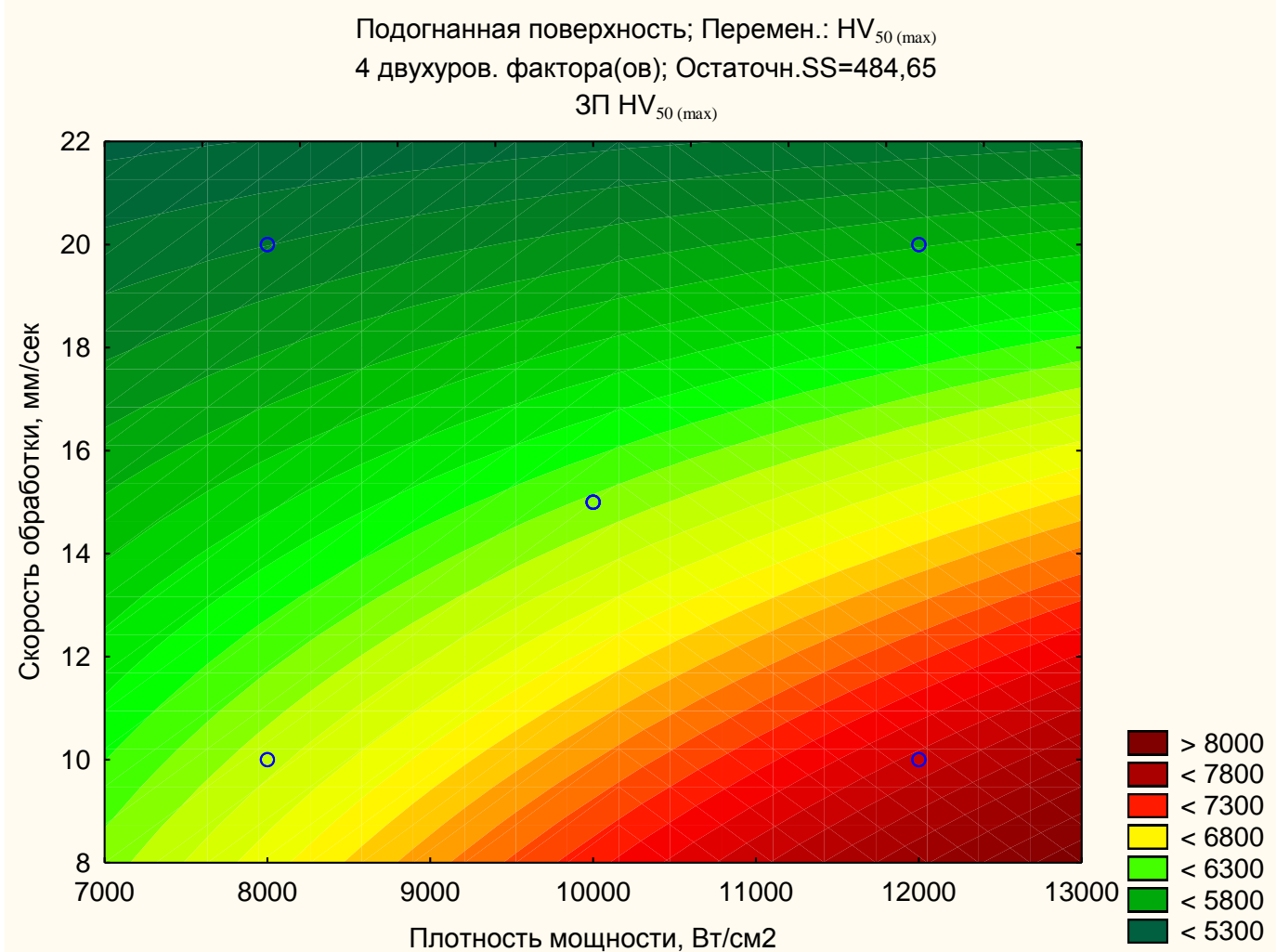

Рисунок 7 - Изменение микротвердости в зависимости от скорости обработки и плотность мощности и («Центр» - 0; температуры отпуска - 600 $\left.{ }^{\circ} \mathrm{C}\right)$

Максимальные значения микротвердости достигаются при плотности мощности более 1,2 $\mathrm{BT} / \mathrm{cm}^{2}$ и скорости обработки менее $10 \mathrm{~mm} / \mathrm{c}$.

В настоящем исследовании проверено, что при режиме $W=1,2 \quad \mathrm{BT} / \mathrm{cm}^{2}$ и $\quad v=10 \mathrm{Mм} / \mathrm{c}$ микротвердость составит 7532 МПа, в случае снижения скорости обработки и увеличении плотности мощности прогнозируется получение значений микротвердости свыше 8000 МПа.

\section{Выводы}

На поверхности упрочненной зоны микротвердость имеет более низкие значения, что связано с выделением остаточного аустенита. Далее микротвердость линейно возрастает, стабилизируясь на определенной глубине. В переходной зоне микротвердость резко снижается. Приведена типичная полученная зависимость распределения микротвердости по глубине ванны.

Рассмотрен механизм изменения микротвердости в зоне ее максимальных значений. Установлено влияние количества и дисперсности карбидной фазы на микротвердость. Показано, что микротвердость выше при лазерной обработке сталей с сорбитной исходной структурой.
Выявлено наличие стационарных областей при лазерной обработке, в которых скорость практически не влияет на получаемую микротвердость при определенных значениях температуры отпуска и плотности мощности. Показано, что при увеличении плотности мощности лазерной обработки температура отпуска, при которой достигается стационарный режим (микротвердость имеет постоянные значения), снижается.

Изучен характер изменения значений максимальной микротвердости в зависимости от режимов лазерного излучения. Наибольшее значение микротвердости возможно получить при плотности мощности $1,2 \cdot 10^{4} \quad \mathrm{BT} / \mathrm{cm}^{2}$ и скорости перемещения лазерного луча $10 \mathrm{~mm} / \mathrm{c}$ при температуре отпуска стали 38ХНЗМФА $t_{\text {omn }}=600^{\circ} \mathrm{C}$ и оно составляет 7532 МПа. В случае повышения плотности мощности и снижения скорости обработки прогнозируется получения микротвердости более 8000 МПа.

Метод математического планирования экспериментов позволяет получить довольно полную картину об изменении параметра отклика рассматриваемой системы и существенно упрощает выбор оптимального режима комплексной термической обработки. 


\begin{tabular}{l|lrl|l|ll} 
& ISRA (India) & $=\mathbf{1 . 3 4 4}$ & SIS (USA) & $=\mathbf{0 . 9 1 2}$ & ICV (Poland) & $=\mathbf{6 . 6 3 0}$ \\
Impact Factor: & ISI (Dubai, UAE) $=\mathbf{0 . 8 2 9}$ & PUHU (Russia) $=\mathbf{0 . 2 3 4}$ & PIF (India) & $=\mathbf{1 . 9 4 0}$ \\
& GIF (Australia) & $\mathbf{0 . 5 6 4}$ & ESJI (KZ) & $=\mathbf{1 . 0 4 2}$ & IBI (India) & $\mathbf{4 . 2 6 0}$
\end{tabular}

\section{References:}

1. Gavrilov GN (2011) Osobennosti formirovanija struktury stalej pri lazernom termicheskom cikle [Tekst]/ Gavrilov G.N., Kastro V.A., Braujer I.B., Beljaev E.S.//Zagotovitel'nye proizvodstva $\mathrm{v}$ mashinostroenii.- 2011.-№12.p.38-41.

2. Kostromin SV (2013) Lazernaja zakalka rezhushhih kromok nozhej dlja obrabotki drevesiny [Tekst]/ Kostromin S.V., Beljaev E.S.//Aktual'nye voprosy sovremennoj tehniki i tehnologii. Sbornik dokladov XIII-j Mezhdunarodnoj nauchnoj konferencii.Lipeck,2013.-p.59-61.

3. Grigor'janc AG, Shiganov IN, Misjurov AI (2006) Tehnologicheskie processy lazernoj obrabotki: Ucheb. Posobie dlja vuzov/ Pod red. A.G.Grigor'janca.-M.: Izd-vo MGTU im. N.Je.Baumana, 2006.-664 p.

4. Beljaev ES (2015) Struktura i svojstva metallostekljannyh materialov na osnove poroshka karbonil'nogo zheleza [Tekst] / Beljaev E.S., Kolosova T.M., Alekseev V.A., Makarov N.V., Getmanovskij Ju.A.// Fundamental'nye issledovanija. - 2015. - № 4. - p. 22-27.
5. Beljaev ES (2016) Povyshenie iznosostojkosti rezhushhego instrumenta $\mathrm{s}$ plastinami iz tverdogo splava T15K6 [Tekst] / Beljaev E.S., Pavlov S.I., Svidenko E.V.// Uprochnjajushhie tehnologii i pokrytija. - 2016. - № 3. - p. 6-9.

6. Sorokin VG, Volosnikova AV, Vjatkin SA, et al. (1989) Marochnik stalej i splavov / Pod obshh. red. V. G. Sorokina. - M.: Mashinostroenie, 1989. - 640 p.

7. Zubchenko AS, Koloskov MM, Kashirskij JV, et al. (2003) Marochnik stalej i splavov. 2-e izd. dop. i ispr. / Pod obshh. red. A. S. Zubchenko. - M.: Mashinostroenie, 2003. - 784 p.

8. Lahtin JM, Leont'eva VP (1980) Materialovedenie: Uchebnik dlja mashinostroitel'nyh vuzov - 2-e izd., pererab. i dop. - M.: Mashinostroenie. 1980. - 493p.

9. Lahtin JM (1983) Metallovedenie i termicheskaja obrabotka metallov — 3-e izd., pererab. i dop. M.: Metallurgija. 1983. - 359p.

10. Novikov II (1974) Teorija termicheskoj obrabotki metallov. Uchebnik. 2-e izd. Novikov I.I. M., «Metallurgija», 1974, 400p. 